\title{
CONFERÊNCIA INTERNACIONAL INTERREG CROSS-BORDER MANAGEMENT SPAIN-PORTUGAL AND SWEDEN-NORWAY
}

EdUARdo MEdeIros ${ }^{1}$

LuÍs MORENO ${ }^{1}$

Realizada a 6 de Maio de 2009 na Universidade de Lisboa (UL), no Anfiteatro III da FLUL, esta conferência foi organizada pelo Centro de Estudos Geográficos desta Universidade (CEG), sendo o primeiro evento internacional realizado já no âmbito do Instituto de Geografia e Ordenamento do Território (IGOT-UL), após a sua criação, como nova unidade orgânica da UL, em 17 de Março de 2009. A realização da conferência visou aprofundar o conhecimento, a reflexão, o debate e a troca de experiências sobre o processo de cooperação transfronteiriça em duas das regiões de fronteira mais antigas da Europa, aproveitando a presença em Portugal de um grupo de técnicos e académicos nórdicos, incluindo responsáveis pela implementação do Programa INTERREG-A Suécia-Noruega.

Como encontro científico e técnico, contou com cerca de 60 participantes, provenientes de Portugal, Espanha, Suécia e Noruega, maioritariamente representantes institucionais de organismos ligados à gestão territorial e ao desenvolvimento regional. O painel de oradores incluiu representantes do governo português (IFDR-MAOTDR), do Programa INTERREG-A (Sue-Nor) e da Associação Europeia de Regiões Fronteiriças (AEBR), para além de universitários. Entre estes inclui-se um investigador do CEG que apresentou alguns resultados de um estudo comparativo sobre o processo de cooperação transfronteiriça nos dois programas INTERREG-A (Portugal-Espanha e Noruega-Suécia) nos últimos 16 anos.

A Abertura da Conferência foi efectuada por Teresa Barata Salgueiro, à data Presidente da Comissão Instaladora do IGOT-UL. Na perspectiva da recepção aos visitantes, em particular dos nórdicos, que mostraram antecipadamente estar interessados no passado e presente da Universidade de Lisboa, a Professora T. B. Salgueiro fez uma breve introdução sobre a história da Universidade, referindo a sua fundação em Lisboa no séc. XIII, as transferências entre Lisboa e Coimbra por parte de diferentes soberanos e o nascimento das escolas da Universidade de Lisboa em meados do século XIX, assumidas como Faculdades com a República, em 1911. Dos aspectos mais ligados à actualidade, começou por abordar o surgimento dos primeiros estudos universitários de Geografia na década de 1930, associados à disciplina de História, mas também a separação dos dois cursos nos anos 1970, sem que o de Geografia tenha deixado de se manter na FLUL, muito influenciado

1 Universidade de Lisboa, Centro de Estudos Geográficos (CEG), Núcleo de Investigação Estratégias e Políticas Territoriais (NEST). 
pela escola francesa. Indicou, não obstante, que o curso teve várias reformas, que apostaram cada vez mais na aplicação da Geografia (da formação de professores aos trabalhos para o planeamento), na resposta às necessidades gerais do país e do mercado de trabalho. Assim, nos últimos anos os cursos superiores de Geografia passaram a ter muito mais estudantes, em diferentes escolas (para além de Lisboa, na UL e depois na UNL e na Universidade Lusófona de Humanidades e Tecnologias (ULHT), também no Porto, Évora e Minho). Concluiu referindo que a UL reconheceu recentemente a grande importância dos estudos ligados ao território e, como consequência, foi criada uma nova unidade autónoma: o IGOT-UL, que arranca com o Departamento de Geografia e o CEG, mas que se pretende que seja uma plataforma de saberes que possa agregar outros cursos e outros centros de investigação.

Seguiu-se uma breve apresentação do CEG, efectuada pelo seu Director, Diogo de Abreu, referindo que esta unidade de investigação, fundada em 1943, se orienta para a Geografia e os estudos do território, em especial de Portugal e dos antigos territórios coloniais, mas também, desde há uns anos e no contexto de parcerias, de diferentes territórios, europeus e não só, pelo que o CEG mantém ligações com instituições de vários continentes. Mostrou igualmente que o CEG possui variados meios de apoio à investigação, servindo numerosos projectos, actividades e ligações com vários centros de investigação internacionais, pelo que o número de investigadores tem vindo a aumentar gradualmente (62 em 2003 e 121 em 2008), trabalhando sobretudo nas áreas da Geografia Humana, Regional, Física e Geo-ecologia. A concluir, abordou a prevista continuação do crescimento e desenvolvimento das actividades do CEG, com a melhoria dos recursos e a incidência em vários eixos de investigação, que foram mencionados, pelo que apontou um futuro implicado na consolidação de dez núcleos de pesquisa, continuando o trabalho de interdisciplinaridade com outros grupos fora da UL e, fundamentalmente, com o estrangeiro.

A matéria específica da Conferência, teve início com a intervenção de Dina Ferreira, Vice-presidente do Instituto Financeiro para o Desenvolvimento Regional (IFDR) e em representação do Governo português. Começou por abordar a Cooperação Transfronteiriça, na perspectiva da sua importância para o desenvolvimento regional, assim como o funcionamento do IFDR, que é a autoridade de certificação no âmbito do QREN para o FEDER e o Fundo de Coesão. Considerou que, para o actual período de programação (2007-13), prosseguindo uma abordagem inovadora, Portugal assumiu integrar o objectivo da cooperação territorial europeia como parte integrante do QREN, como instrumento-chave para a prossecução da política de coesão e do processo de integração europeia. Salientou também a especial importância dada pelo governo português ao tema da cooperação transfronteiriça, no sentido do fortalecimento das relações entre os dois países ibéricos. No âmbito do Programa Operacional de Cooperação Transfronteiriça Espanha-Portugal (POCTEP), exerce as funções de correspondente nacional (participa no acompanhamento do programa, colabora na promoção de projectos, faz a articulação com as CCDR e o secretariado técnico, verifica as despesas concretizadas pelos beneficiários portugueses e funciona como autoridade de certificação). Referiu que o POCTEP foi feito de uma forma muito participada, tendo sido criado um grupo de trabalho conjunto (Portugal e Espanha) para a elaboração do programa de forma inovadora, assente no princípio da subsidiariedade, respeitando os princípios orientadores do QREN: concentração, selectividade, viabilidade e sustentabilidade económico-financeira, co-responsabilidade e simplificação. Valorizaramse igualmente os projectos que produzissem resultados e impactos significativos nas economias e nas condições de vida das populações, deixando marcas inequívocas no território, mesmo para além do período de programação. 
As prioridades do POCTEP puderam ser sintetizadas em três componentes: (i) competitividade territorial; (ii) sustentabilidade territorial; (iii) fortalecimento da cooperação social e institucional. Estas prioridades estão devidamente articuladas com os Programas Operacionais Regionais que complementam este tipo de acções. O reforço da coesão económica e social do espaço de fronteira entre Portugal e Espanha valoriza o capital acumulado durante as três gerações do Programa INTERREG, que desempenhou um papel-chave para a aproximação dos dois países ibéricos, tendo o mesmo passado por diversas etapas evolutivas que resultaram: (i) no reforço da componente imaterial, (ii) no alargamento do leque de agentes envolvidos no processo de cooperação, (iii) no aprofundamento da natureza das intervenções de cooperação (tudo pensado desde o início e gerido em parceria), (iv) no reforço das estruturas conjuntas de cooperação. O presente Programa representa um novo salto qualitativo, tendo os sub-programas regionais dado lugar a áreas de cooperação e, ainda, a uma intervenção centrada nos objectivos da cooperação e da gestão conjunta de infra-estruturas, equipamentos e serviços que traduzam um aprofundamento considerável do carácter transfronteiriço do programa. O papel das comunidades de trabalho dos gabinetes de iniciativas transfronteiriças, associações de municípios e outras entidades é considerada fundamental, seja no domínio da programação, seja em todo o processo subsequente. Realce foi também dado à intenção de criar um Observatório de Cooperação Transfronteiriça, de modo a estabelecer dispositivos de observação articulados em rede, tendo em vista antecipar e acompanhar os processos de cooperação local, regional e transfronteiriça, bem como aferir o seu impacto sobre o desenvolvimento regional e local. Foi ainda destacado um novo instrumento jurídico, os Agrupamentos Europeus de Cooperação Territorial (AECT), que visam facilitar e promover a cooperação territorial. Em Portugal foi já constituído o agrupamento Galiza-Norte de Portugal (o $3^{\circ}$ da UE). Foi também proposta a criação de mais 4 (AECT Duero-Douro; Zasnet; Alto Tâmega-Ourense; Guadiana). Apesar de todos estes notáveis avanços persistem obstáculos administrativos à actividade das empresas e ao bem-estar dos cidadãos. A fronteira limita a ocupação de equipamentos estruturais, prejudica a rentabilidade social de muitos investimentos públicos e fracciona o planeamento territorial integrado da malha ibérica.

Esta conferência teve lugar num momento propício, pois ocorre numa altura caracterizada por avanços significativos no processo de cooperação transfronteiriça entre Portugal e Espanha: (i) reunião da comissão mista Luso-espanhola (Ayamonte - Novembro 2008), (ii) reunião ministerial Luso-espanhola (Viana do Castelo - 20 de Dezembro 2008); (iii) 24 a cimeira Luso-espanhola (Zamora - 22 de Janeiro 2009); (iv) $1^{\text {a }}$ reunião ministerial de cooperação transfronteiriça (Zamora - 30 de Maio 2009). A estratégia a seguir passa pelo (i) desenvolvimento de projectos-âncora, (ii) o encorajamento das autoridades regionais para coordenarem a abertura de concursos em prol do desenvolvimento regional integrado nos espaços de fronteira, (iii) o estabelecimento de princípios a que os AECT devem obedecer, (iv) a necessidade de eliminar custos públicos de contexto, (v) o reconhecimento da conveniência em estabelecer uma posição negocial conjunta tendo em vista a discussão na UE sobre o futuro da política de coesão. Por fim, foi afirmado que a actual situação de crise económica internacional exige respostas articuladas que potenciem a alavancagem de recursos financeiros e a indução do crescimento do emprego, favorecendo a promoção de iniciativas complementares nas NUTS III portuguesas e espanholas transfronteiriças. Assim, concluiu-se que "o que formos capazes de realizar neste contexto, provavelmente com carácter pioneiro na Europa, poderá revelar-se numa excelente mais-valia negocial, para o pilar da cooperação transfronteiriça e o futuro da política de coesão". 
O representante da Associação Europeia de Regiões Fronteiriças (AEBR), Paulo Silva, fez uma intervenção sobre a importância desta associação para a promoção da cooperação transfronteiriça na UE. Deste modo, começou por dar relevo ao facto de a AEBR ser uma entidade com mais de 50 anos, com um número crescente de associados (10 em 1971 e 100 em 2009, na mesma linha de que "a tradição da cooperação europeia é muito antiga e tem vindo a crescer"), e que tem funcionado como um laboratório para a integração europeia, tendo a intenção de "exportar a sua experiência" para outros pontos do globo (América Central e África). Assim, na sua opinião, a AEBR tem sido muito importante para promover o desenvolvimento das regiões de fronteira, estando envolvida em muitos dos projectos emblemáticos da cooperação territorial europeia (Agenda Territorial Europeia, AECT, etc.), e tendo relações privilegiadas com o Parlamento Europeu, o Comité das Regiões, a Comissão Europeia, o Comité Económico e Social, etc. Havendo "inúmeras formas de promover a cooperação transfronteiriça", sendo as regiões fronteiriças muito diversas, referiu o Alentejo quanto a dois exemplos de protocolos assinados, um com a Extremadura (1992) e outro com a Andaluzia (2001), visando integrar as regiões e as populações, promover a integração europeia e atenuar as grandes diferenças ainda existentes. Isto apesar de as diferenças político-administrativas entre o Alentejo e a Extremadura "sempre terem criado barreiras à cooperação transfronteiriça". Esta, podendo não ser uma prioridade nacional, é contudo fundamental para a integração europeia, criando valores acrescentados do ponto de vista institucional e socioeconómico. Sendo o período 2007-2013 uma das últimas oportunidades para a cooperação assistida, é previsível que, com o todo o esforço que tem vindo a ser feito, com estruturas e os instrumentos entretanto criados, deixará de existir a necessidade de se canalizarem verbas para manter esta cooperação.

A conferência prosseguiu com a intervenção de Eduardo Medeiros, investigador do CEG (núcleo NEST), comparando dois Programas INTERREG-A da UE: Portugal-Espanha e Suécia-Noruega, matéria que tem vindo a estudar no âmbito da sua tese de doutoramento. Começando essa comparação pelo enquadramento territorial, fez notar as semelhanças que ambos os Programas apresentam (cerca de $1 / 4$ do território e de $11 \%$ da população das respectivas penínsulas). Também no domínio dos indicadores demográficos, ambas as regiões caracterizam-se, em geral, pela existência de baixas densidades populacionais, elevadas taxas de mortalidade e baixas taxas de natalidade, embora a Região de Fronteira entre Portugal e Espanha (RFPE) apresente valores mais preocupantes, à semelhança, aliás, do que acontece na comparação entre os indicadores de coesão socioeconómica, visto que esta região apresenta um rendimento per capita muito inferior ao da Região de Fronteira entre a Suécia e a Noruega (RFSN), além de taxas de desemprego mais elevadas, uma elevada percentagem de população no sector primário $(10 \%)$ e uma baixa percentagem de população com ensino superior (18,7\%). A grande diferença dos dois Programas está na alocação de recursos financeiros, que foi 10 vezes superior na RFPE (até 2006) e na gestão dos projectos, que teve um peso muito superior quanto à participação da sociedade civil e das universidades na RFSN, em contraste com o forte peso das entidades estatais na RFPE (municípios - Portugal; entidades regionais - Espanha). Esta situação revela, desde logo, a maior maturidade do programa escandinavo (e das estruturas socioterritoriais nesta península), onde o processo de cooperação é muito anterior ao estabelecimento da iniciativa comunitária INTERREG-A, justificando assim a maior percentagem de projectos que tiveram mais de uma fase nesse Programa (11,7\% vs 3,5\% na RFPE).

O mesmo investigador realçou também que os projectos âncora no Programa Ibérico direccionaram-se essencialmente para a melhoria das acessibilidades rodoviárias trans- 
fronteiriças, enquanto na RFSN estes foram muito mais heterogéneos e tiveram um financiamento muito inferior. Uma questão colocada foi: "todos estes investimentos conseguiram inverter o cenário crescente de exclusão territorial das duas regiões de fronteira estudadas?" Para responder, foi apresentado um índice sintético, construído a partir de indicadores socioeconómicos e posteriormente aplicado a todo o espaço peninsular, a fim de medir a evolução dos mesmos no período de vigência do INTERREG-A (19902006). Os resultados mostraram que, infelizmente, em ambas as regiões de fronteira estudadas continua a verificar-se, em geral, um afastamento em relação à média do crescimento peninsular. Não obstante, E. Medeiros considerou que o INTERREG-A tem vindo a contribuir para que esse panorama não seja tão negro e, também, que tem sido muito importante para o reforço da articulação territorial, nomeadamente na dimensão relacional (estabelecimento de redes de contactos), e ainda na dimensão morfológica (melhoria da articulação física), que foi particularmente visada no Programa Ibérico ( $42 \%$ do investimento foi destinado à melhoria da rede rodoviária transfronteiriça, contra os $10 \%$ do Programa Escandinavo). De facto, também neste domínio o Programa Escandinavo mostrou um grau de maturidade mais elevado, com 37\% dos recursos financeiros orientados para a competitividade económica.

Outra comparação dos dois programas, com base nos vários parâmetros que suportam um modelo proposto de cooperação transfronteiriça, mostrou igualmente que o Programa Escandinavo apresenta uma intensidade de cooperação muito mais forte que o Ibérico, que resulta essencialmente do facto da cooperação transfronteiriça entre Portugal e Espanha ter sido iniciada praticamente com o lançamento to INTERREG-A, em 1990. Mesmo assim, em alguns domínios este parece mostrar uma evolução mais rápida que o seu congénere escandinavo, o que pode ser testemunhado pela constituição de dois AECT e a proposta para a constituição de mais três, além de outros projectos emblemáticos, como a partilha de um hospital por parte das populações fronteiriças em algumas valências (Badajoz) e da aposta em projectos estruturantes como o Laboratório Ibérico Internacional de Nanotecnologia (Braga) e o Centro Ibérico para as Energias Renováveis (Badajoz). Finalmente, E. Medeiros alertou para os desafios futuros da Cooperação Transfronteiriça, devendo-se ter presentes as mudanças climáticas, o aproveitamento crescente das fontes de energia renováveis, o crescente despovoamento de alguns espaços fronteiriços menos dinâmicos e, ainda, os desafios inerentes ao processo de globalização.

$\mathrm{Na}$ intervenção que se seguiu, Erik Hagen, co-responsável pela Gestão do Programa INTERREG-A Suécia-Noruega, fez uma breve apresentação deste, além de uma referência ao trabalho de Eduardo Medeiros, que motivou a recente visita ao território de fronteira Ibérico e a realização desta conferência. Apontou que o objectivo da visita passou essencialmente pela aprendizagem de boas práticas que estão a ser levadas a cabo no Programa Ibérico. Realçou também que, apesar da Noruega não ser um membro de pleno direito da UE, isso não tem impedido que $70 \%$ das importações e exportações deste país passem pela UE. Assim, apesar de não participarem no debate político deste espaço político, participam em algumas das suas entidades regionais, como a AEBR.

Prosseguiu, referindo que o governo e as regiões da Noruega têm apoiado fortemente a cooperação com a Suécia. O programa escandinavo tem também apoiado projectos âncora, que têm demonstrado ser mais-valias para o desenvolvimento do território. As regiões de fronteira da Noruega são centrais no país mas na Suécia essas regiões são mais remotas. Uma das principais tarefas do Programa INTERREG-A Swe-Nor é a de reforçar o desenvolvimento socioeconómico das áreas mais deprimidas. Tal como a RFPE, a RFSN apresenta muitas áreas pouco povoadas; assim, um dos principais objectivos estratégicos do Programa 
é a promoção da atractividade e uma boa qualidade de vida, para estimular a entrada de população na região de fronteira. No INTERREG-IV registaram-se alguns desencontros na definição da estrutura do programa, tendo em conta a localização da sua administração. Foram tomadas algumas medidas inovadoras: (i) parcerias regionais; (ii) aumento substancial do volume financeiro de cada projecto (de $400.000 €$ a $1.200 .000 €$, em média). Os responsáveis pelo Programa acompanham de perto os outros programas europeus, para assim poderem "copiar" algumas das melhores ideias (também da AEBR), e dão muita importância ao valor acrescentado que os programas podem ter em várias dimensões (social, económica, cultural, etc.). Da mesma forma, o Programa recorre ao conhecimento de vários académicos de valor reconhecido no desenvolvimento de estratégias inovadoras. Foi também mostrado um projecto relacionado com a promoção das energias renováveis, a ser criado no cluster tecnológico de Lillestrøm (um automóvel movido a hidrogénio), que segue os pressupostos da Agenda de Lisboa. Outro projecto emblemático relaciona-se com a promoção da música rock na região de Hedmark (Noruega). Para finalizar, referiu também que a integração dos dois estados escandinavos é forte e que têm sido levados a cabo projectos inovadores com a articulação de perspectivas top-down e bottom-up.

A intervenção final coube a Peter de Souza, professor e investigador da Universidade de Hedmark, Noruega. Na sua apresentação referiu que trabalha na região RFSN e que recebeu Eduardo Medeiros no seu local de trabalho, com quem teve uma discussão bastante proveitosa. Foi um dos gestores dos programas INTERREG-A, o que lhe deu muita experiência e conhecimento do INTERREG. Participou também num projecto para a elaboração de um manual de boas práticas para a cooperação transfronteiriça. Desse projecto resultaram inúmeras entrevistas a gestores de projectos, das quais foi possível retirar algumas ideias interessantes: (i) foi constantemente referida a importância da criação de redes; (ii) a necessidade de preparar bem o terreno para a implementação dos projectos; (iii) a maior parte dos projectos teve imenso sucesso, pelo que não se detectaram muitos problemas; (iv) conhecer as dificuldades na região é muito importante; (v) os projectos "têm de ter uma alma" para agregar as populações e os políticos; (vi) os projectos devem ser levados a cabo pelas pessoas certas e com a preparação adequada. Existem dois tipos de promotores de projectos: (i) querem tudo de acordo com regras bem estabelecidas, (ii) querem uma maior flexibilidade do processo. Uma das características do INTERREG III-A foi a quantificação de quase tudo o que existe em relação aos projectos, o que tanto permite compará-los como constituir, também, mais um factor burocrático adicional, com inconvenientes... Apesar de não se terem registado problemas de maior, existiram alguns constrangimentos de pequena monta relacionados com: (i) o marketing dos projectos (excesso de vaidade na apresentação dos mesmos); (ii) o excesso de tempo que leva a aprovação de alguns projectos; (iii) a falta de atravessamentos rodoviários em condições; (iv) a ideia de que os dois povos escandinavos são muito parecidos pode causar problemas (por exemplo, falta de cuidado com pequenas diferenças culturais, relacionadas com a língua). Sobre este último preconceito, fez notar que a ideia de que os suecos "são mais formais e burocráticos e os noruegueses mais caóticos" tem alguma verdade, mas nem sempre é assim. A terminar a sua intervenção salientou que a "vida depois dos projectos" é muito importante e deve ser tida em conta pelos promotores dos mesmos, juntamente com a criação de redes de contactos. 